\title{
France seeks scientists' views on reform
}

[PARIS] Prime minister Lionel Jospin launched a national consultation on the organization of French research last week. He has commissioned the exercise after earlier reform plans by science minister Claude Allègre stalled in the face of opposition from the research community.

A parliamentary mission will culminate in a national debate in Paris in June, and is expected to present Jospin with "concrete proposals" the following month. The mission is led by two socialist members of the national assembly, Pierre Cohen (Haute-Garonne) and Jean-Yves Le Deaut (Meurthe-et-Moselle), a former head of the Parliamentary Office of Scientific and Technological Choices.

Tension over Allègre's plans is still running high (see Nature 397, 463; 1999). The main unions representing scientists suspect that the ministry may simply pay lip service to the outcome of the consultation - Allègre had previously rejected demands by researchers for a national public debate.

Last week the unions called on researchers to support a national day of protest on 11 May, to secure a commitment from the government that no reforms would be undertaken before the end of the consultation. In particular, they are demanding the postponement of an interministerial meeting on research due to be held on 18 May. They argue that the decision not to defer this meeting suggests that the ministry is likely to to ignore the consultation and push ahead with its own reform plans.

But Vincent Courtillot, director-general of research at the ministry, dismisses such concerns. He claims that the interministerial meeting will deal only with strategic research themes and industrial research.

"The CIRST [ conseil interministériel sur la recherche scientifique et technologique] will not be centred on the items included in the parliamentary mission, though it is likely to mention that actions on helping young researchers and promoting scientific mobility will be taken after the CohenLe Deaut report has been submitted," says Courtillot.

Similarly, Le Deaut says that he would not have accepted the mission had he felt it was a tactic by the government to defuse opposition. He says he has assurances that Jospin will take the outcome seriously and that it will not "gather dust in a drawer".

The mission is being assisted by a steering committee of more than 20 researchers and industrialists, including former science minister Hubert Curien and Philippe Desmarescaux, director-general of RhônePoulenc.

In a break with tradition, the committee also includes several young scientists. Finding ways to give young scientists greater independence is one of the five stated goals of the mission, and the theme of a debate in Paris on 9 June.

The others goals are to propose ways of increasing the mobility of researchers; to improve links between research agencies and universities; and to analyse procedures for recruitment and evaluation.

In hearings being held over the next few weeks, the mission will consult about 100 leading research figures, while wider input will be sought using an Internet forum (see http://www.mission-cohenledeaut.org). A series of public meetings in various French cities is also to be organized.

Declan Butler

\section{Germany says it will come on board Earth observation mission}

[MUNICH] German research minister Edelgard Bulmahn announced last week that the country will participate "substantially" in the European Space Agency's (ESA's) 'optional' Earth observation and launcher development programmes.

Her announcement has eased fears that Germany's contribution, which could make or break the programmes, might not emerge. But Bulmahn has not yet revealed how much Germany will contribute - that sum will be negotiated at next week's meeting of European space ministers.

The ministerial meeting has been delayed for nearly a year because of Germany's financial problems. It is being held to discuss the levels of resources and broad content of ESA's programmes over the next five years.

Bulmahn has long complained that heavy commitments to the International Space Station, which the Social Democrat-Green coalition government inherited from its predecessor, left no spare money for joining in new, unmanned space activities. These include Earth observation, one of the government's highest scientific priorities.

But, after a detailed review of potential savings in each part of the German space budget, Bulmahn says she has found room for manoeuvre. In addition, she says, the overall German space budget will be raised over the next few years, and she expects to win a DM10 million (US\$5.4 million)

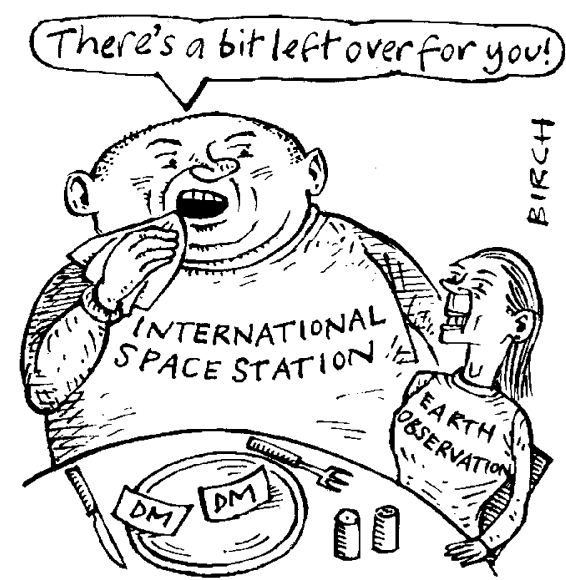

increase to the 1999 budget of DM1.6 billion over the next few months.

Money for space activities is tight in other ESA member states as well. So prospects are bleak for an increase in resources for the 'mandatory' science programme, which ESA's director-general Antonio Rodotá calls the "backbone" of the agency.

Resources have been capped for the past four years, squeezing budgets for approved missions almost to breaking point (see Nature 395, 732; 1998). Rodotá will ask ministers to approve an internal reallocation of funds to maintain 1998 purchasing power until 2003, to ensure that all planned missions are launched on schedule.

Following Germany's announcement,
ESA officials expect to be able to raise 759 million euros (US\$804 million) at the ministerial meeting for the optional Earth observation programme, which has been redesigned on the 'faster, cheaper, better' principle (see Nature 392,$425 ; 1998$ ).

The programme has a strong scientific element, with its Living Planet component aiming to achieve a launch every year. Small scientific missions will be interspersed with medium-sized 'core' scientific missions.

Selections for the first of both types of mission are currently being made by the scientific community. Front runners include a small ice altimetry mission called Cryosat, which will measure ice topography and ice motion, and a 'core' gravity mission called GOCE (Gravity Field and Steady State Ocean Circulation Explorer), which will measure irregularities in the Earth's mass distribution through gravity-field variations, with the aim of better understanding ocean circulation.

Space ministers will also discuss telecommunications and launcher plans next week. The latter include an extension of Ariane $\mathrm{V}$ and the development of smaller launchers to maintain international competitiveness. Ministers will be asked to finally approve plans to develop a secondgeneration Global Navigation Satellite System in partnership with the European Commission, at a cost to both partners of 500 million euros.

Alison Abbott 